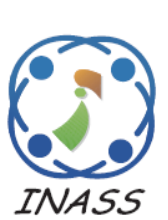

\author{
International Journal of \\ Intelligent Engineering \& Systems
}

http://www.inass.org/

\title{
Performance Evaluation of Association Rule Mining with Enhanced Apriori Algorithm Incorporated with Artificial Bee Colony Optimization Algorithm
}

\author{
Ramani Selvanambi ${ }^{1^{*}}$ \\ Jaisankar Natarajan ${ }^{1}$ \\ ${ }^{l}$ Vellore Institute of Technology University, Vellore, India \\ * Corresponding author’s Email: ramani.s@vit.ac.in
}

\begin{abstract}
In data mining, association rules are produced in view of solid relations and regularities existing among the variables in extensive exchanges. These association rules go for extricating connections, frequent patterns and associations among the item sets in exchanges. Association rules are connected for use in different zones, for example, media transmission, hazard administration and so forth. One such territory where the association rules are vital is the stock market. In stock marketing, picking the right stock relies on upon the genuine stock quality and the capacity to pick the stock is urgent as it impacts the profit of investors. In this work, the proposed technique develops a novel and effective way to deal with producing optimal stock rules to help in the stock market prediction by utilizing Enhanced Apriori algorithm and Artificial Bee Colony Optimization (ABC) algorithm. In the result profit of PP, EMA, ROC and RSI for min-support 3, 4, 5 and 6 individually in rule mining for HCL stock market dataset is appeared with correlation of GA-Apriori algorithm, AGA- Enhanced Apriori algorithm and ABC- Enhanced Apriori algorithm. From this Artificial Bee Colony $(\mathrm{ABC})$ optimization algorithm is performed when contrasting and different strategies and grant that strong association rules to be produced.
\end{abstract}

Keywords: Stock rule, Apriori algorithm, Enhanced Apriori algorithm, Artificial bee colony optimization.

\section{Introduction}

In stock exchanging markets, income development rate is a vital pointer for investors to predict the developing firms later on. The developing firms stand for specific firm that can progressing create and more get increases profit per offer [1]. Stock market recommender framework taking into account Association Rule Mining (ARM) that prescribes an arrangement of stocks. The target of this recommender framework is to support stock market traders, singular financial specialists and asset chiefs in their choices by proposing interest in a gathering of value stocks when solid confirmation of conceivable benefit from these exchanges is accessible [2]. Stock list gauging is one of the significant exercises of money related firms and private speculators in settling on venture choices. Since stock markets is a mind boggling, transformative, and nonlinear element framework its forecast is considered as a testing errand [3]. Stock is the most famous of money related business sector instruments. It can be characterized as an indication of capital interest of a man or an undertaking in an organization or a restricted risk organization [4]. Stock costs rely on upon different components, the imperative ones being the market sentiment, performance of the industry, earning results and projected earnings, takeover or merger, introduction of a new product or introduction of an existing product into new markets, share buy-back, announcements of dividends or bonuses, addition or removal from the index [5]. Stock market prediction has been a region of extraordinary enthusiasm because of the capability of getting an exceptional yield on the put cash in a brief timeframe [6]. The simple availability to databases with recorded costs makes the feeble structure market effectiveness test a less demanding undertaking to actualize contrasted and the productivity trial of the other two structures [7]. The disclosure of specific examples, which are 
trademark for time arrangement and consequently have an uncommon significance, is a critical errand in the region of time arrangement examination, and comparatively, the revelation of certain example, to be specific of association rules, is a vital assignment in the investigation of value-based information [8]. To anticipate hazard and return variables precisely, the successful components should be distinguished. Truth be told, one of the key issues of stock expectation outline lies on the best way to choose agent highlights for forecast [9]. Evolutionary computation for the most part develops people with a specific end goal to build their wellness, and it acquires the ideal or close ideal people which speak to activity rules when they are utilized as a part of specialist control frameworks [10]. Stock market is a dynamic and complex framework with uproarious, non-stationary information, making the forecast of future stock costs one of the all the more difficult issues [11]. In the scope of developing markets, China is without a doubt one of a kind from multiple points of view and worth the exertion of exact work both for its own purpose (it has numerous exceptional elements) and for the light it can toss on the relationship amongst effectiveness and business sector advancement. The Chinese stock market has existed for scarcely 10 years and is becoming exceptionally rapidly.[12]Association Rule Mining is a standout amongst the most vital systems of data mining whose principle point is to concentrate associations among sets of things or items in valuebased databases.[13] Techniques of association rule mining can be utilized to find obscure or shrouded connection between things found in the database of transactions.[14] Association rule discovers relationship between apparently disconnected information among an expansive arrangement of information things. In this way, affiliation principle can simply locate a potential relationship amongst components and convey astonishment to us. Apriori algorithm is one of the compelling algorithm for frequent item sets mining and association rule learning.[15] The paper was one of the pioneers in utilizing association rules to think about if any relations exist between stocks gathered under various sectors.[16] Existing looks into give a deficient perspective of the idea float issue in stock market because of confinements in investigation approach and element choice. [17] The motivation behind the study is to gauge and examine organization stock value developments by executing the association rule-mining algorithm to concentrate standards of relationship between developments of organization stock costs from time to time.[18]To upgrade the predictive power of the monetary time arrangement models various computational knowledge based procedures like the Artificial Neural Network, fuzzy inference system, Support Vector Machine, Relevance Vector Machine hybridized with the money related time arrangement models have been proposed in the literature.[19] Soft computing methods are generally connected to stock market problems. They offer valuable apparatuses in anticipating loud situations like stock markets, catching their non-straight behavior.[20] In later past artificial bee colony algorithm have been produced to show the savvy practices of honeybee swarms and connected for settling combinatorial sort problems.[21] Artificial Bee Colony (ABC) is a curiosity in the region of algorithms optimization, exciting interest and better results thought about than different algorithms, as Genetic Algorithms (GA) and Particle Swarm Optimization (PSO), in a few territories of examination. Consequently, pick the $\mathrm{ABC}$ to locate the best arrangement of lags.

Economic analysts who provide in stock markets usually are not alert of the stock market performance. They are facing the problem of stock trading, as they do not know which stocks to purchase and which to sell in order to gain more profits. These kinds of issues are solved with creating optimal stock rules in stock market prediction.

In this paper, for generating optimal stock rules to aid the stock market prediction using Enhanced Apriori algorithm and Artificial Bee Colony optimization algorithm.

The remaining of this paper is organized as follows. Section 2 outlines survey of related works, section 3 gives proposed approach, section 4 gives results and discussion and talk at last in section 5 shows the conclusion.

\section{Related Works}

Patil et al. [22] had proposed a framework that will give forecasts about the offer share market, which will take after two fundamental stages, which are piece construct association mining and further in light of more optimization and prediction will be given by genetic algorithm. The significant favorable position of utilizing section based mining is that, it amasses every one of the properties once and performs operations bunch insightful rather than single qualities which brings about more summed up tenets which are further exceedingly optimized using genetic algorithm as its time space intricacy is not exactly whatever other algorithm and give forecast of little scale organizations in light of 
exchange information of expansive scale and also little scale organizations.

Nayak et al. [23] had proposed the hidden framework models of time arrangement forecast are intricate and not known from the earlier; consequently, exact and fair-minded estimation can't be constantly accomplished utilizing surely understood straight strategies. The paper shows an Artificial Chemical Reaction Neural Network (ACRNN), which utilizes Artificial Chemical Reaction Optimization (ACRO) to prepare the MLP models for anticipating the stock market indices. The hidden inspiration for utilizing ACRO is the capacity to defeat the issues of merging, parameter setting and over fitting and to precisely estimate monetary time arrangement information notwithstanding when the fundamental framework procedures are commonly nonlinear. After broad experimentation, it is watched that the ACRNN method shows critical changes in prediction accuracy over the MLP approach.

Shingo Mabu et al. [24] had expected that arrangement is a noteworthy exploration field in pattern recognition and numerous strategies have been proposed to upgrade the speculation capacity of order. Ensemble learning is one of the techniques which improve the order capacity by making a few classifiers and settling on choices by joining their grouping comes about. Then again, when we consider stock exchanging issues, patterns of the markets are imperative to choose to purchase and offer stocks. Consequently, in this paper, to improve the execution of the stock exchanging framework, outfit learning system of rule-based evolutionary algorithm utilizing multi-layer perceptron (MLP) is proposed, where several rule pools for stock trading are made by rule-based evolutionary algorithm, and compelling rule pools are adaptively chosen by MLP and the chose guideline pools agreeably settle on choices of stock exchanging. In the reenactments, it is illuminated that the proposed strategy demonstrates higher benefits or lower misfortunes than the technique without troupe learning and purchase and hold.

Kianoush Fathi Vajargah et al. [25] had proposed in the predictions of total stock list, are confronted with a few parameters as they are questionable in future and they can experience changes, and this instability has a couple dangers, and for a genuine examination, the calculations ought to be performed under danger conditions. The predictions of total stock list and esteem at danger by this technique are preferable and more correct over Monte Carlo strategy. This learn at first assesses irregular differential condition of geometric
Brownian movement and its recreation by semi Monte Carlo technique, and after that its application in the predictions of total stock market index and esteem at danger can be assessed.

Shubhangi Umbarkar et al. [26] had proposed to predict direction of stock price precisely was exceptionally significant for market dealers or investors to boost their benefits. Data mining strategies have been effectively appeared to create high anticipating exactness of stock value development and comparing signals. Prediction of stock cost is the action of deciding future condition of the stock cost by utilizing different procedures. In introduced work Data Mining Technique, for example, Association Rule Mining is utilized for prediction of stock market. Prediction is relies on upon specialized exchanging markers and shutting costs of the stock. Rules are characterized by produced by every specialized exchanging marker and mapped over the present date inquiry to create the signs like purchase, offer or holds the shares.

Sheik Shaugat Abdullah et al. [27] had proposed that target of the examination is to arrange or conjecture the stock market from the general financial specialist's perspective. In the initial segment played out an overview on the greater part of the notable data mining markers, executed the algorithms and calculated the accuracy by applying them on verifiable information. At long last, were connected association rules mining to gather the chose (in view of exactness) indicator algorithms to think of a model to expand the general precision. However rousing certainty is accomplished much better results from our recommended model than other similar indicator algorithms or system.

Guoqiang $\mathrm{Li}$ et al. [28] had foreseen that Artificial Bee Colony province calculation (ABC), which is enlivened by the rummaging conduct of honey bee swarm, is an organic motivated improvement. It indicates more powerful than genetic algorithm (GA), particle swarm optimization (PSO) and ant colony optimization (ACO).ABC is great at investigation however poor at misuse, and its joining velocity is likewise an issue now and again. What's more, to further balance search forms, the change types of the utilized honey bees and the spectator ones are diverse in the second speeding up coefficient. Results show that PS-ABC has a faster convergence speed like I-ABC and preferable pursuit capacity over other applicable strategies for all capacities.

Tsung-Jung Hsieha et al. [29] had proposed a coordinated framework where wavelet changes and Recurrent Neural Network (RNN) in view of Artificial Bee Colony (ABC) algorithm (called 
ABC-RNN) are joined for stock value gauging. The framework contains three phases. The Artificial Bee Colony algorithm (ABC) is used to advance the RNN weights and inclinations under a parameter space outline. For representation and assessment purposes, this study alludes to the recreation consequences of a few worldwide stock markets, including the Dow Jones Industrial Average Index (DJIA), London FTSE-100 Index (FTSE), Tokyo Nikkei-225 Index (Nikkei), and Taiwan Stock Exchange Capitalization Weighted Stock Index (TAIEX). As this reproduction comes about illustrate, the proposed framework is profoundly encouraging and can be actualized in a continuous exchanging framework at anticipating stock costs and maximizing profits.

\section{Proposed Approach}

In this proposed work, devise a novel and effective way to deal with produce optimal stock rules to help in the stock market prediction by utilizing Enhanced Apriori algorithm and Artificial Bee Colony Optimization (ABC) algorithm. Here, our work depends on the money related dataset by means of technical indicators. Through the technical indicators, the vital datasets are created. At first, the recorded database contains closing value, highest value and lowest value of the stock market index for $\mathrm{n}$ periods. These authentic datasets must be directed with the goal that it is adaptable for the further clarifications. The data analysis that is utilized in our proposed study uncovers the exertion of stock market.

\subsection{Association rule mining}

The association among the items is exceptionally appropriate for basic leadership and powerful marketing in the business field. Target of discovering association rules is to find cooccurrence relationship called as associations. In our work, the association rule mining technique is utilized for effective data mining as a part of the stock market. It has the need to separate fascinating correlations, associations, frequent patterns between the arrangements of things in the stock market database. Here the ARM is connected to create set of stock principles from the four investigated datasets. The association rule can be represented as $\mathrm{X}=>\mathrm{Y}$, here $\mathrm{X}$ and $\mathrm{Y}$ are the item sets. $\mathrm{X}$ called as predecessor while $\mathrm{Y}$ is called as resulting. The making of continuous item sets and association rules are accomplished through this mining procedure.
There are two huge measures for association rules, support and confidence. These requirements are exceptionally helpful to pick the incessant item sets in the expansive stock market databases. The limits of backing and certainty are predefined by clients to wipe out those principles which are not reasonable. The limits are called as min-support and min-confidence. The backing of an association rule is the rate of records that encase $\mathrm{XuY}$ to the aggregate number of records in the database. The certainty of the association rule is the rate of the quantity of exchanges that encase $\mathrm{XuY}$ to the aggregate number of records, which include $X$. The backing infers frequency of happening examples and certainty is the quality of suggestion.

\subsection{Data analysis through technical indicators}

The examination of the organization's recorded database is performed to make the data adaptable for further advancement. There are numerous technical indicators reasonable to bolster in stock market forecasting. In our work, the data elucidation is performed in light of the four technical indicators. These are numerically framed beneath.

Table.1 Technical indicators

\begin{tabular}{|c|c|c|c|}
\hline $\begin{array}{l}\text { Sl. } \\
\text { No }\end{array}$ & $\begin{array}{l}\text { Technical } \\
\text { Indicators }\end{array}$ & Symbol & Formula Representations \\
\hline 1 & Pivot Point & PP & $\begin{array}{l}\qquad P P=\frac{H+C+L}{3} \\
\text { H- Highest stock value } \\
\text { C - Closing Price } \\
\text { L - Lowest stock value }\end{array}$ \\
\hline 2 & $\begin{array}{l}\text { Exponential } \\
\text { Moving } \\
\text { Average }\end{array}$ & EMA & $\begin{array}{l}E M A=E M A(u-1)+ \\
\varphi\left[c_{u}-E M A(u-1)\right] ; \\
\text { where } \quad m<u \leq n \\
\text { Where, } \varphi=\frac{2}{m+1} \\
m-\text { Smoothing Period } \\
c_{u}-\text { Closing Price }\end{array}$ \\
\hline 3 & $\begin{array}{l}\text { Relative } \\
\text { Strength } \\
\text { Index }\end{array}$ & RSI & $\begin{array}{c}R S I=100\left(1-\frac{1}{R S}\right) \\
\text { RS- Relative Strength }\end{array}$ \\
\hline 4 & $\begin{array}{l}\text { Rate of } \\
\text { Change }\end{array}$ & $\mathrm{ROC}$ & $\begin{array}{l}\text { ROC }_{u}=\frac{\text { close }_{\text {today }}-\text { close }_{u}}{\text { close }_{u}} \\
\qquad ; m<u \leq n \\
\text { n-number of rules } \\
\text { close today - Today Close } \\
\text { price } \\
\text { close } \\
\text { days ago }\end{array}$ \\
\hline
\end{tabular}


Pivot point (PP) is the average of high, low and close prices in the market before the period of trading.

Exponential moving average (EMA) is the method to smoothen the data by eliminating the noise.

Rate of Change (ROC) is the indicator that shows the difference between today's closing price and the close price of $\mathrm{N}$ days ago.

Relative Strength Index (RSI) compares upward movements in closing price to downward movements over a selected period. The indicator should not be confused with relative strength (RS).

\subsection{Enhanced Apriori algorithm for mining association rules}

Apriori is the notable algorithm utilized for mining associations among things in the huge stock market databases. A general Apriori is intended to work on databases containing exchanges. At first the successive item sets for the whole databases are made by min-support values. At that point through this successive item sets and min-confidence values, the best stock standards were resolved from the dataset. By Apriori, the mined principles which have greatest file estimations of turn point, exponential moving normal, relative strength index and rate of progress were gotten for stock market prediction. In typical Apriori, the time calculation many-sided quality is high.

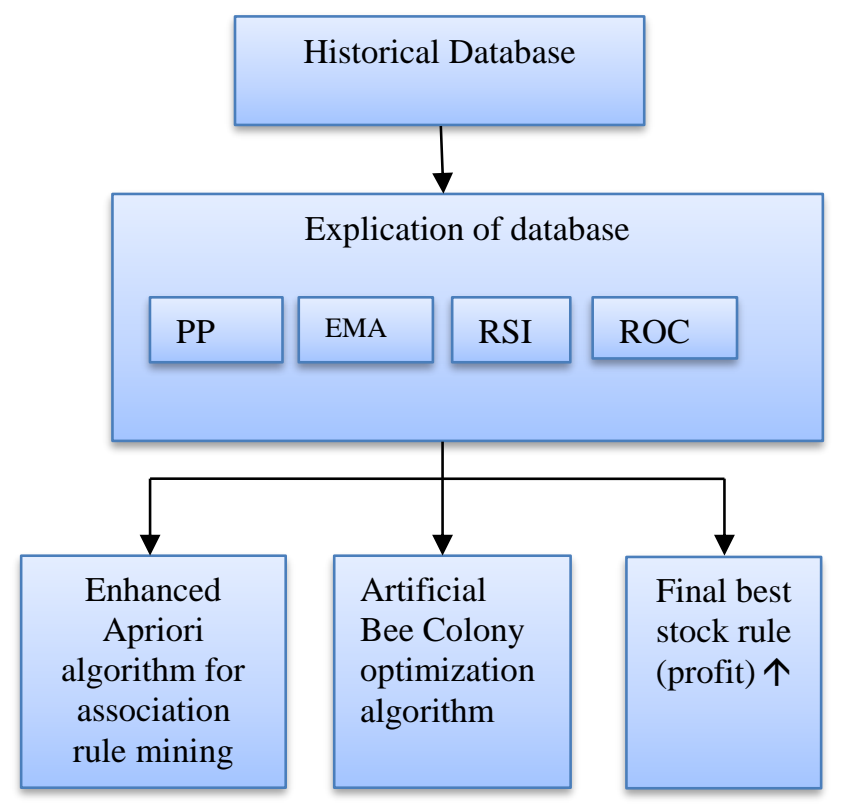

Figure.1 Block diagram for proposed method
In the proposed work, the upgraded Apriori algorithm has been connected for mining association rules and the number of frequent itemset is 7 in light of the fact that the data was figured for 7 days. Each incessant itemset is figured from its earlier values with min-support edge. In this way, undesirable rules are wiped out by this technique in every exchange and the time calculation multifaceted nature to locate the stock principle was minimized contrasted with typical Apriori algorithm. This resultant mined data will be bolstered to the $\mathrm{ABC}$ with the end goal of creating fine stock principle. The proposed method diagram is shown in figure 1 .

\subsection{Optimization method using ABC algorithm}

Artificial Bee Colony algorithm is one among the recently defined algorithms motivated by the intelligent behavior of honey bees.

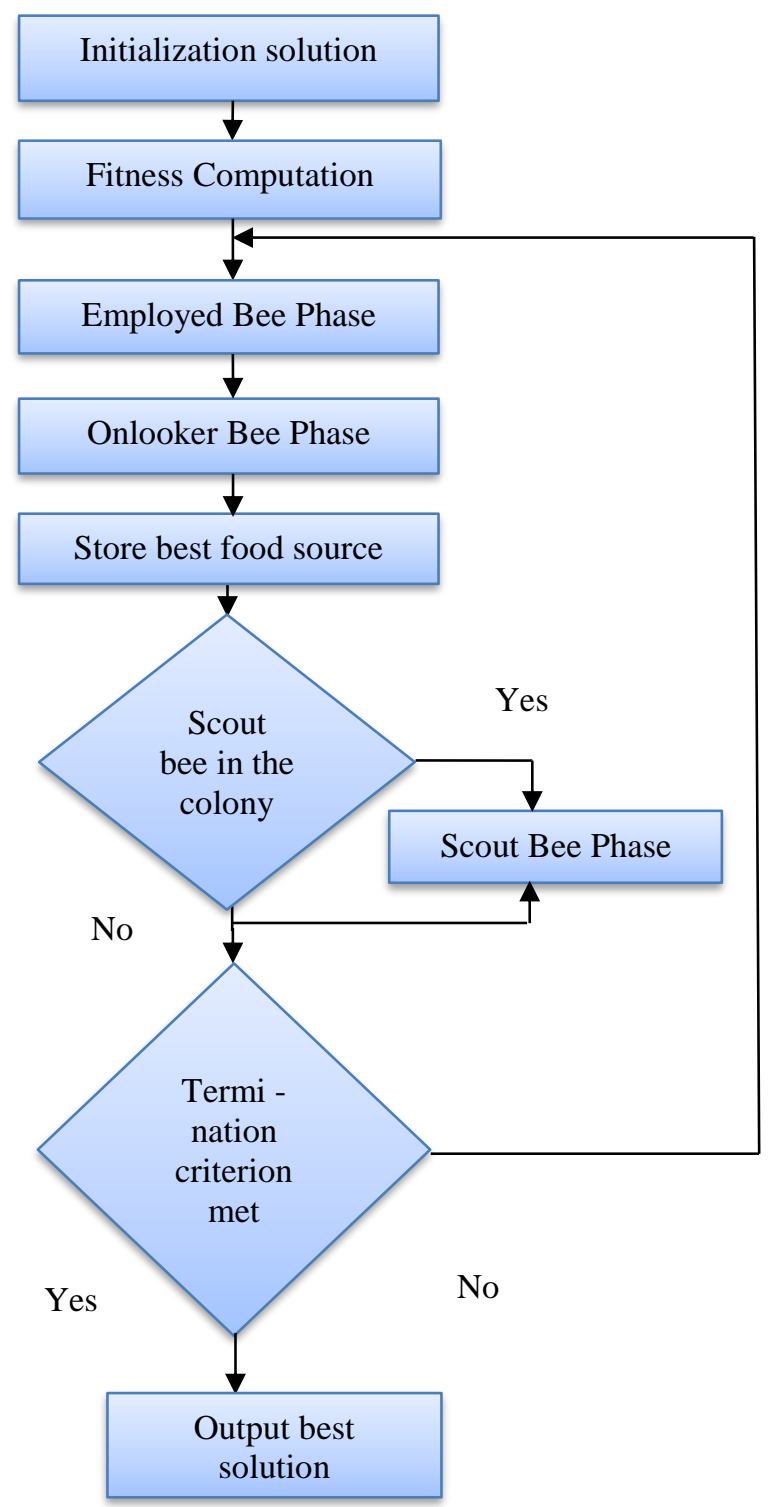

Figure.2 Flowchart for ABC algorithm 
$\mathrm{ABC}$ as an improvement apparatus gives a populace based inquiry method in which people called nourishments positions are adjusted by the simulated honey bees with time and the honey bee's point is to find the spots of sustenance sources with high nectar sum lastly the one with the most noteworthy nectar. In $\mathrm{ABC}$ framework, simulated honey bees fly around in a multidimensional pursuit space and a few (utilized and spectator honey bees) pick nourishment sources relying upon the experience of themselves and their home mates, and change their positions. A few (scouts) fly and pick the nourishment sources arbitrarily without utilizing knowledge. On the off chance that the nectar measure of another source is higher than that of the past one in their memory, they retain the new position and overlook the past one. In this manner, ABC framework consolidates neighborhood look techniques, did by utilized and passerby honey bees, with worldwide hunt strategies, oversaw by spectators and scouts, endeavoring to adjust investigation and abuse handle.

\subsubsection{Initial solution generation}

The initial solution $\left(\mathrm{S}_{\mathrm{ij}}\right)$ is generated randomly.

\subsubsection{Fitness computation}

The Fitness computation is the process, which utilizes equation (1) to find the fitness of the individual solution, and this process is evolved as follows.

$$
F_{i}=\min \left(\sum_{k=1}^{N} H_{j}\left(P_{j}\right)\right)
$$

The Minimum of fitness is considered to be best fitted.

\subsubsection{Employed bee}

Employed bee is the process where the new solution is generated under the given equation.

$$
H_{i j}=S_{i j}+\Phi_{i j}\left(S_{i j}+S_{k j}\right)
$$

Equation (2) is utilized to generate the new element in the defined solution $\mathrm{i}$, where as in $\phi_{\mathrm{ij}}, \phi$ range from $[-1,1]$ and $i j$ indicates the index position and $k$ determines randomly $k \in\{1,2 \ldots$ size $(i)\}$ the significance constraint in this process $\mathrm{k} \neq i$. The fitness computation process is held up for evaluating the fitness for the newly generated solution by equation (2). Then the greedy selection $\mathrm{D}_{\mathrm{ij}}$ process is performed to retrieve the best solution from the currently generated $\mathrm{H}_{\mathrm{ij}}$ and $\mathrm{S}_{\mathrm{ij}}$.

\subsubsection{Probability calculation}

The Probability calculation $\left(\mathrm{P}_{\mathrm{i}}\right)$ is calculated for the $\mathrm{D}_{\mathrm{ij}}$ as per the process shown below.

$p_{i}=\frac{F_{i}}{\sum_{i=1}^{N} F_{i}}$

The above eqn. (3) is the procedure to discover the probability rate of achieving fitness after the greedy selection process. After consummation of the probability count prepare the accomplished arrangement is in the request that the fitness has higher probability priority rate.

\subsubsection{Onlooker bee}

Consequent to the probability rate calculation, the solution is sorted and regarded as the initial solution for the onlooker bee section. In view of the previously mentioned arrangement, the new solution $\left(D_{i j}\right)$ is assessed by utilizing equation (2) and the fitness is computed for $\mathrm{D}_{\mathrm{ij}}$. Once more, the greedy selection process is performed keeping in mind the end goal to pick the best solution in the midst of the quickly happening onlooker bee solution $\mathrm{D}_{\mathrm{ij}}\left(\mathrm{F}_{\mathrm{i}}\right)$ and probability based greedy solution happening in the past stride.

\subsubsection{Scout bee}

The Scout bee happens when the deceived game plans happen and it is repeated always until beyond what many would consider possible, which will incite the explanation behind discretionary course of action as has happened as of now. In this work, beyond what many would consider possible is set as two, when the left course of action surpasses two, then the already specified subjective game plan satisfying the objectives will happen.

\section{Result and discussion}

In this result section the association rule mining for stock rule prediction utilizing Artificial Bee Colony Optimization algorithm (ABC) was performed. At first the enhanced Apriori performance was contrasted and general Apriori algorithm for every technical indicators exclusively by their min support values. The time taken for 
creating the stock rules by enhanced Apriori algorithm was superior to anything utilizing Apriori algorithm in light of the fact that by Enhanced Apriori algorithm, the unrivaled stock rules just endure in the database. Aside from this, these rules were killed in each regular itemset database. The time calculation for every technical indicator is low with this proposed enhanced Apriori algorithm. These techniques are dissected by utilizing MATLAB programming.

During this assessment, the powerful time for processing the stock rules was produced for every technical indicator in enhanced Apriori algorithm. At that point the last guidelines of the stock from enhanced Apriori were further connected to Artificial Bee Colony Optimization (ABC) algorithm. The $\mathrm{ABC}$ was given the last stock rule to the stock market. The execution of the last stock rule was assessed by applying benefit examination in this work. The profit is computed from the aftereffects of the enhanced Apriori algorithm with $\mathrm{ABC}$ and Apriori algorithm with $\mathrm{ABC}$ and the profit got with the two strategies are contrasted and each other. The equation for figuring profit is given in eqn. (4).

\section{Profit $=$ Avg (Consequent - Antecedent $)$ $\times$ Number of rules occurrences}

In eqn. (4), the profit value is figured by recognizing the ensuing and predecessor part of the principles and it duplicating with the number of rules happened. The profit was assessed with min support values for all the technical indicators independently. For instance, to ascertain the profit for turn point based rule mining, at first need to check the last govern of the pivot point in the stock database. Through the database, can get the forerunner and resulting values from every one of the events of the standards for pivot point. At that point, take the normal for it. By eqn. (4) the profit was computed exclusively for pivot point, exponential moving normal, powerful quality record and rate of progress with the min support 3, 4, 5 and 6 in this work. In trial usage, the HCL Company's stock market database was utilized for the rule mining.

From table 2, the profit of PP, EMA, ROC and RSI for min-support 6 respectively in rule mining for HCL stock market dataset has been shown. In this for GA-Apriori algorithm the EMA value is 40799.46, PP value is 31470.47 , ROC value is 31511.83 and RSI value is 40000 . For AGA-EAP algorithm the EMA value is 470873.4, $\mathrm{PP}$ is 149349.3, ROC is 118698.7 and RSI value is 187572.6. For ABC-EAP algorithm the EMA value is 438590.2 , PP is $8224498.1, \mathrm{ROC}$ is 127666.9 and RSI value is 678440.9. In figure 3 the graph for profit of PP, EMA, ROC and RSI for min-support 6 is shown. From this $A B C$ algorithm is performed better comparing with other two techniques.

Table. 2 The profit of PP, EMA, ROC and RSI for min support of 6 respectively in rule mining for HCL stock market dataset

\begin{tabular}{|l|c|c|c|c|}
\hline \multirow{2}{*}{$\begin{array}{l}\text { Tech- } \\
\text { nique }\end{array}$} & \multicolumn{4}{|c|}{ Profit } \\
\cline { 2 - 5 } & EMA & PP & ROC & RSI \\
\hline $\begin{array}{l}\text { GA- } \\
\text { Apri }\end{array}$ & 40799.46 & 31470.47 & 31511.83 & 40000 \\
\hline $\begin{array}{l}\text { AGA } \\
\text {-EAP }\end{array}$ & 470873.4 & 149349.3 & 118698.7 & 187572.6 \\
\hline $\begin{array}{l}\text { ABC- } \\
\text { EAP }\end{array}$ & 438590.2 & 8224498 & 127666.9 & 678440.9 \\
\hline
\end{tabular}

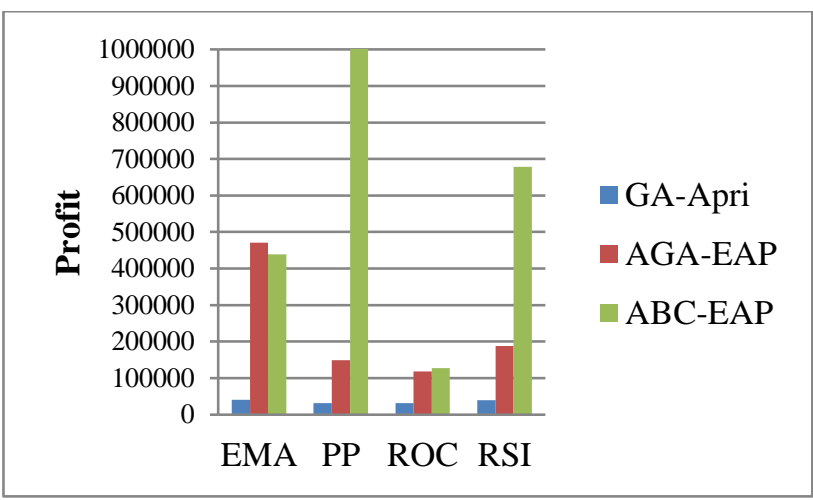

Figure.3 Profit of PP, EMA, ROC and RSI for minsupport 6

Table.3 The profit of PP, EMA, ROC and RSI for minsupport of 5 respectively in rule mining for HCL stock market dataset

\begin{tabular}{|c|c|c|c|c|}
\hline \multirow{2}{*}{$\begin{array}{c}\text { Tech- } \\
\text { nique }\end{array}$} & \multicolumn{4}{|c|}{ Profit } \\
\cline { 2 - 5 } & EMA & PP & ROC & RSI \\
\hline $\begin{array}{c}\text { GA- } \\
\text { Apri }\end{array}$ & 40799.4 & 31470.4 & 31511.8 & 40000 \\
\hline $\begin{array}{c}\text { AGA- } \\
\text { EAP }\end{array}$ & 61758.4 & 136637.1 & 41953.5 & 12823438 \\
\hline $\begin{array}{l}\text { ABC- } \\
\text { EAP }\end{array}$ & 8224498 & 43859093 & 166632 & 67848406 \\
\hline
\end{tabular}




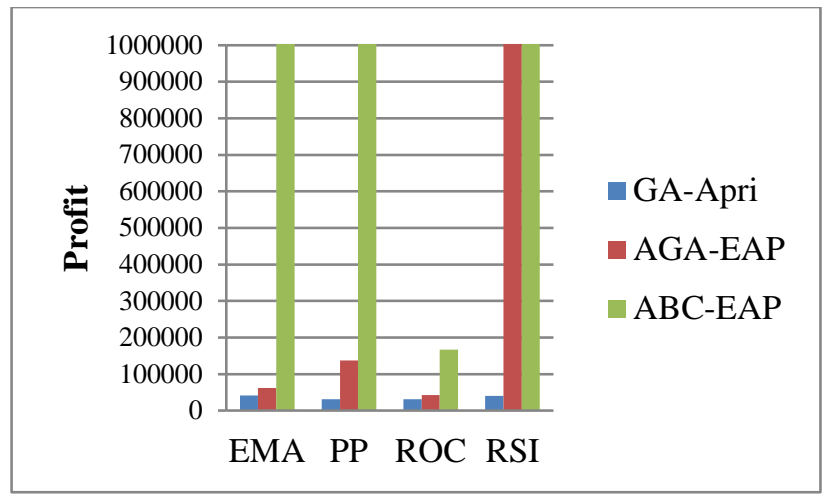

Figure.4 Profit of PP, EMA, ROC and RSI for minsupport 5

Table. 4 The profit of PP, EMA, ROC and RSI for minsupport of 4 respectively in rule mining for HCL stock market dataset

\begin{tabular}{|c|c|c|c|c|}
\hline \multirow{2}{*}{$\begin{array}{c}\text { Tech- } \\
\text { nique }\end{array}$} & \multicolumn{4}{|l}{ Profit } \\
\cline { 2 - 5 } & EMA & PP & ROC & RSI \\
\hline $\begin{array}{c}\text { GA- } \\
\text { Apri }\end{array}$ & 40799.4 & 2000 & 31511.8 & 325822.0 \\
\hline $\begin{array}{c}\text { AGA- } \\
\text { EAP }\end{array}$ & 145550.3 & 4385909.3 & 129662 & 2469532 \\
\hline $\begin{array}{l}\text { ABC- } \\
\text { EAP }\end{array}$ & 822498.1 & 45859093 & 137666 & 6256784 \\
\hline
\end{tabular}

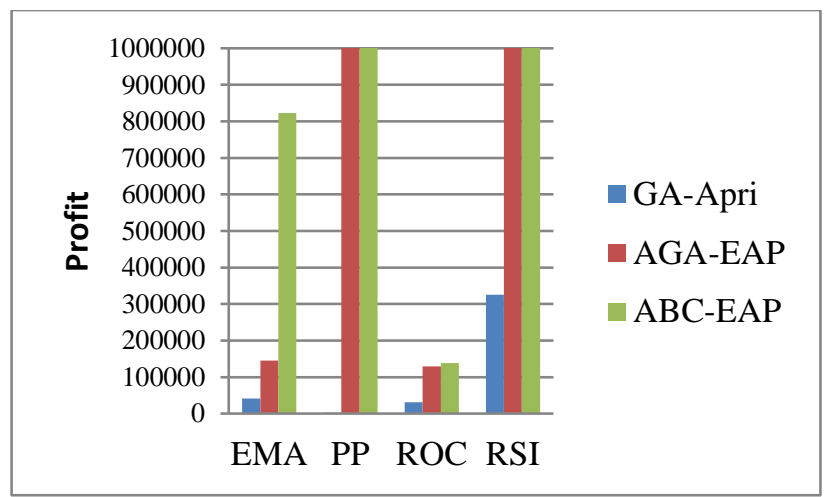

Figure.5 Profit of PP, EMA, ROC and RSI for minsupport 4

From table 3, the profit of PP, EMA, ROC and RSI for min-support 5 respectively in rule mining for HCL stock market dataset has been shown. In this for GA-Apriori algorithm the EMA value is 40799.46, PP value is 31470.47 , ROC value is 31511.83 and RSI value is 40000 . For AGA-EAP algorithm the EMA value is $61758.48, \mathrm{PP}$ is 136637.1, ROC is 41953.5and RSI value is 12823438. For ABC-EAP algorithm the EMA value is $8224498, \mathrm{PP}$ is 43859093 , ROC is 166632.6 and RSI value is 67848406 . In figure 4, the graph for profit of PP, EMA, ROC and RSI for min-support 5 is shown.

From table 4, the profit of PP, EMA, ROC and RSI for min-support 4 respectively in rule mining for HCL stock market dataset has been shown. In this for GA-Apriori algorithm the EMA value is 40799.46043, PP value is 2000, ROC value is 31511.82654and RSI value is 325822.0109. For AGA-EAP algorithm the EMA value is 145550.393 , $\mathrm{PP}$ is 4385909.322 , ROC is 129662.3858and RSI value is 2469532.38. For ABC-EAP algorithm the EMA value is $822498.1, \mathrm{PP}$ is 45859093.22 , ROC is 137666.9625and RSI value is 6256784.189. In figure 5, the graph for profit of PP, EMA, ROC and RSI for min-support 4 is shown. From this $A B C$ algorithm is performed better comparing with other two techniques.

From table 5 the profit of PP, EMA, ROC and RSI for min-support 3 respectively in rule mining for HCL stock market dataset has been shown. In this for GA-Apriori algorithm the EMA value is 40799.46043, PP value is 31470.47244 , ROC value is 5000and RSI value is 325822.0109 . For AGAEAP algorithm the EMA value is 470873.3552 , PP is 1826903.761 , ROC is 127666.9625 and RSI value is 187572.5973. For ABC-EAP algorithm the EMA value is 5620217.6, PP is 43859093.22, ROC is 157666.9625and RSI value is 444370.0401. In figure 6 the graph for profit of PP, EMA, ROC and RSI for min-support 3 is shown. From this $A B C$ algorithm is performed better comparing with other two techniques.

Table.5 The profit of PP, EMA, ROC and RSI for minsupport of 4 respectively in rule mining for HCL stock market dataset

\begin{tabular}{|c|c|c|c|c|}
\hline \multirow{2}{*}{$\begin{array}{c}\text { Tech- } \\
\text { nique }\end{array}$} & \multicolumn{4}{|c|}{ Profit } \\
\cline { 2 - 5 } & EMA & PP & ROC & RSI \\
\hline $\begin{array}{c}\text { GA- } \\
\text { Apri }\end{array}$ & 40799.46 & 31470.47 & 5000 & 325822 \\
\hline $\begin{array}{c}\text { AGA- } \\
\text { EAP }\end{array}$ & 470873.35 & 1826903.7 & 127666 & 187572 \\
\hline $\begin{array}{c}\text { ABC- } \\
\text { EAP }\end{array}$ & 5620217.60 & 43859093 & 157666 & 444370 \\
\hline
\end{tabular}




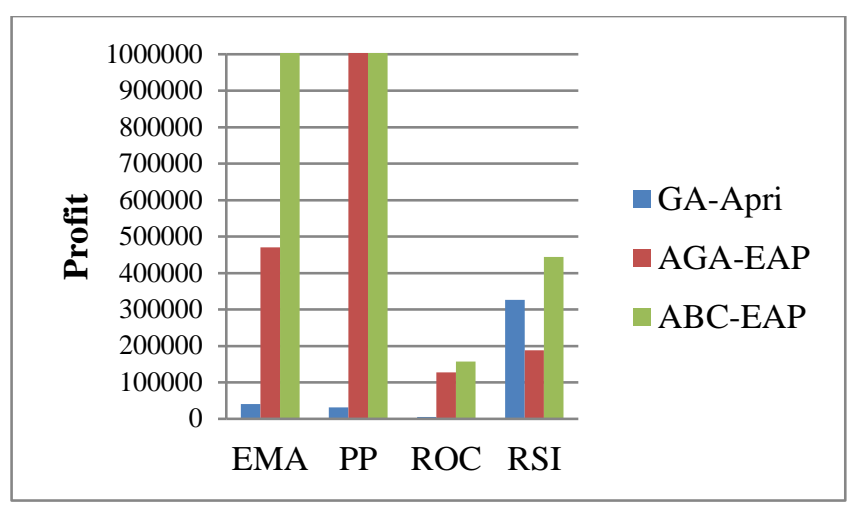

Figure.6 Profit of PP, EMA, ROC and RSI for minsupport 3

\section{Conclusion}

In this conclusion segment clarified from the outcome that connected the enhanced Apriori algorithm with Artificial Bee Colony optimization (ABC) algorithm to locate the best stock rule. The execution of the work was assessed as far as profit qualities. The trial consequences of this stock predictions demonstrate that the rules chose by the enhanced Apriori and Artificial Bee Colony optimization $(\mathrm{ABC})$ algorithm are more powerful and solid than those got with the general Apriori, GA and AGA. In this manner, created utility stock rules would likewise be exceptionally strong in taking choices in stocks bargains and in this way, in prediction. This serves to the investors in improving determination of stock rules for their speculation. This proposed algorithm was executed in the working platform of MATLAB. In future other diverse procedures can be joined to enhance the stock prediction rules.

\section{References}

[1] C. Cheng and Y. Chen. "Fundamental Analysis of Stock Trading Systems using Classification Techniques", In: 2007 International Conference on Machine Learning and Cybernetics, Vol. No. 3, pp. 1377-1382, 2007.

[2] P. Paranjape-Voditel and U. Deshpande, "A Stock Market Portfolio Recommender System Based on Association Rule Mining", Applied Soft Computing, Vol. No. 2, pp. 1055-1063, 2013.

[3] C. M. Anish and B. Majhi, "Hybrid Nonlinear Adaptive Scheme for Stock Market Prediction using Feedback FLANN and Factor Analysis", Journal of the Korean Statistical Society, Vol. No. 45, pp. 64-76, 2016.
[4] A. A. Arafah and I. Mukhlash, "The Application of Fuzzy Association Rule on Co-Movement Analyze of Indonesian Stock Price", Procedia Computer Science, Vol. No.59, pp.235-243, 2015.

[5] P. Paranjape-Voditel and U. Deshpande. "An Association Rule Mining Based Stock Market Recommender System", In: Emerging Applications of Information Technology (EAIT), 2011 Second International Conference, pp. 2124, 2011.

[6] B. B. Nair, M. Minuvarthini, Sujithra. B and V. P. Mohandas, "Stock Market Prediction using a Hybrid Neuro-Fuzzy System", Advances in Recent Technologies in Communication and Computing (ARTCom), 2010 International Conference , pp. 243-247, 2010.

[7] A. Zapranis and P. Tsinaslanidis, "A novel, rulebased technical pattern identification mechanism: Identifying and evaluating saucers and resistant levels in the US stock market", Expert Systems with Applications, Vol. No.39, pp. 6301-6308, 2012.

[8] T. Schluter and S. Conrad, "About the Analysis of Time Series with Temporal Association Rule Mining", In: Computational Intelligence and Data Mining (CIDM), 2011 IEEE Symposium, pp. 325-332, 2011.

[9] S. Barak and M. Modarres, "Developing an Approach to Evaluate Stocks by Forecasting Effective Features with Data Mining Methods", Expert Systems with Applications, Vol. No. 11, pp.1325-1339, 2015.

[10] S. Mabu, K. Hirasawa, M. Obayashi and T. Kuremoto, "Enhanced Decision Making Mechanism of Rule-Based Genetic Network Programming for Creating Stock Trading Signals", Expert Systems with Applications, Vol. No. 40, pp. 6311-6320, 2013.

[11] Y. Kim and D. Enke, "Developing a Rule Change Trading System for the Futures Market using Rough Set Analysis", Expert Systems with Applications, Vol. No. 59, pp. 165-173, 2016.

[12] N. Groenewold, S.H.K. Tang and Y. Wu, "The Profitability of Regression-Based Trading Rules for the Shanghai Stock Market", International Review of Financial Analysis, Vol. No.17, pp.411-430, 2008.

[13] M. Suthar and A. Ranavadiya, "An Insight into Various Techniques on Association Rule Mining using Multi Objective Genetic Algorithm", International Journal of Advent Research in Computer and Electronics, Vol. 2, No. 12, pp.1-8, 2015. 
[14] H. L. Ghazi and M. S. Abadeh, "Mining fuzzy association rules with 2-tuple linguistic terms in stock market data by using genetic algorithm", In: Artificial Intelligence and Signal Processing (AISP), 16th CSI International Symposium, pp. 354-359, 2012.

[15] T. Yang, K. Qian, D. C. Lo, Y. Xie, Y. Shi and L. Tao, "Improve the Prediction Accuracy of Naïve Bayes Classifier with Association Rule Mining", In: Big Data Security on Cloud (BigDataSecurity), IEEE International Conference on High Performance and Smart Computing (HPSC), and IEEE International Conference on Intelligent Data and Security (IDS), 2016 IEEE 2nd International Conference, pp.129-133, 2016.

[16] S. Ulagapriya and P. Balasubramanian, "Study on Inter sector Association rules in National Stock Exchange, India", In: 2015 International Conference on Advances in Computing, Communications and Informatics (ICACCI), pp.859-865, 2015.

[17] Y. Hu, K. Liu, X. Zhang, K. Xie, W. Chen, Y. Zeng and M. Liu, "Concept Drift Mining of Portfolio Selection Factors in Stock Market", Electronic Commerce Research and Applications, Vol. No. 14, pp.444-455, 2015.

[18] H. Widiputra and B. Pahlevi, "Inter-transaction Association Rule Mining in the Indonesia Stock Exchange Market", In: Uncertainty Reasoning and Knowledge Engineering (URKE), 2012 2nd International Conference, pp.149-152, 2012.

[19] R. Dash, P.K. Dash and R. Bisoi, "A Differential Harmony Search Based Hybrid Interval Type2 Fuzzy EGARCH Model for Stock Market Volatility Prediction", International Journal of Approximate Reasoning, Vol. No. 59, pp.81-104, 2015.

[20] T. Anbalagan and S. Uma Maheswari, "Classification and Prediction of Stock Market Index Based on Fuzzy Metagraph", Procedia Computer Science, Vol. No. 47, pp.214-221, 2015.

[21] M. Rout, B. Majhi, U. M. Mohapatra and R. Mahapatra, "An Artificial Bee Colony Algorithm Based Efficient Prediction Model for Stock Market Indices", In: Information and Communication Technologies (WICT), 2012 World Congress, pp.750-754, 2012.

[22] R.V. Patil, G. Y. Tamhane, J. S Dhage, A.B Gawande and S.U. Mogal, "Genetic Based Stock Market Prediction", International Journal of Engineering Science And Innovative Technology, Vol. No.5,2016.
[23] S.C. Nayak, B. B Misra and H.S Behera, "Artificial Chemical Reaction Optimization of Neural Networks for Efficient Prediction of Stock Market Indices", Ain Shams engineering Journal, 2015.

[24] S. Mabu, M. Obayashi and T. Kuremoto, "Ensemble learning of rule-based evolutionary algorithm using multi-layer perceptron for supporting decisions in stock trading problems", Applied soft computing, Vol.36, pp.357-367, 2015.

[25] K.F. Vajargah and M. Shoghi, "Simulation of Stochastic Differential Equation of Geometric Brownian Motion by Quasi-Monte Carlo Method and its Application in Prediction of Total Index of Stock Market and Value at Risk", Mathematical Sciences, Vol. No.9, pp.115-125, 2015.

[26] S.S Umbarkar and S.S. Nandgaonkar, "Using Association Rule Mining: Stock Market Events Prediction from Financial News", International Journal of Science and Research, Vol.4, pp.1958-1963, 2015.

[27] S.S. Abdullah and M.S. Rahaman, "Stock Market Prediction model using TPWS and Association Rules Mining", In: Computer and Information Technology (ICCIT), 2012 15th International Conference, pp.390-395, 2012.

[28] G. Li, P. Niu and X. Xiao, "Development and Investigation of Efficient Artificial Bee Colony Algorithm for Numerical Function Optimization", Applied Soft Computing, Vol. No.12, pp.320-332, 2012.

[29] T. Hsieha, H. Hsiaob and W. Yeh, "Forecasting Stock Markets using Wavelet Transforms and Recurrent Neural Networks: An Integrated System Based on Artificial Bee Colony Algorithm", Applied Soft Computing, Vol. No.11, pp.2510-2525, 2011. 